Istanbul Finance Congress, November 4-5, 2021

\title{
CAMELS PERFORMANCE ANALYSIS OF FOREIGN DEPOSIT BANKS BASED ON COMPONENT FACTOR
}

\author{
DOI: 10.17261/Pressacademia.2021.1487 \\ PAP- V.14-2021(13)-p.57-63
}

\section{Ersan Ozgur}

Türkiye Büyük Millet Meclisi Kamu Denetçiliği Kurumu Ankara, Türkiye ersanozgur@yahoo.com ,ORCID ID: 0000-0002-6165-4556

\section{To cite this document}

Ozgur, E. (2021). CAMELS performance analysis of foreign deposit banks based on component factor. PressAcademia Procedia (PAP), 14, 5763.

Permanent link to this document: http://doi.org/10.17261/Pressacademia.2021.1487

Copyright: Published by PressAcademia and limited licensed re-use rights only.

\section{ABSTRACT}

Purpose- The number of foreign banks entering into the Turkish financial system has increased starting from the 1990s. The foreign capital banks have reached the size of $20 \%$ in the banking sector today. Surveillance and supervision of the foreign banks with a significant scale in the financial system are considered important regarding the financial system.

Methodology- In order to identify the banks' risk status and performance, CAMELS analysis is frequently used within the remote surveillance activity. In this study, CAMELS analysis was conducted with the sample of 12 foreign deposit banks which were established in Turkey and operated between 2009-2019. The CAMELS analysis consists of 6 components, and in the implementation stage, 6 component-oriented analyses were performed as individually for each component. The component identified as the focus in the implementation was determined as weighting $50 \%$, and the other components were evaluated as equally weighted.

Findings- The findings revealed that, in the banks within the scope of the analysis, mostly the profitability component was dominant by years. The change in the profitability was considerably effective on the other components.

Conclusion- Since the profitability component is dominant, the change in the return on assets ratio has a significant impact on other components.

Keywords: CAMELS analysis, audit, performance, foreign deposit banks.

JEL Codes: G17, G21, M42

\section{YABANCI SERMAYELI MEVDUAT BANKALARININ BILEŞEN FAKTÖR ODAKLI CAMELS PERFORMANS} ANALIZi

\section{ÖZET}

Amaç- Türk finans sistemine yabancı bankaların girişi 1990'lı yıllardan itibaren artmaya başlamıştır. Günümüzde yabancı sermayeli bankalar bankacılık sektöründe \%20 düzeyinde bir hacme ulaşmış bulunmaktadır. Finansal sistem içinde önemli seviyede hacmi bulunan yabancı sermayeli bankaların gözetim ve denetimi finansal sistem açısından önemli görülmektedir.

Yöntem- Bankaların risk durumunun ve performansının belirlenmesi için uzaktan gözetim faaliyetinde CAMELS analizi sıklıkla kullanılmaktadır. Bu çalışmada Türkiye'de kurulmuş ve 2009-2019 yılları arasında faaliyette bulunmuş 12 yabancı sermayeli mevduat bankası örnek alınarak CAMELS analizi gerçekleştirilmiştir. CAMELS analizinde 6 bileşen bulunmakta olup, uygulama çalışmasında her bir bileşen için ayrı olmak üzere bileşen odaklı 6 adet analiz yapılmıştır. Uygulamada odak alınan bileşen \%50 ağırlıklı olarak belirlenmiş, diğer bileşenler ise eşit ağırlıklı değerlendirilmiştir.

Bulgular- Elde edilen bulgulara göre analiz kapsamındaki bankalarda yıllar itibariyle büyük ölçüde kârlılık bileşeninin baskın bir yapıda olduğu belirlenmiştir. Kârlılık bileşeninde meydana gelen değişim diğer bileşenlerde büyük ölçüde etkili olmaktadır.

Sonuç- Kârlılık bileşeninin baskın bir yapıda olması dolayısıyla aktif kârlılık oranındaki değişim diğer bileşenlerde büyük ölçüde etkili olmaktadır.

Anahtar Kelimeler: CAMELS analizi, denetim, performans, yabancı sermayeli bankalar.

JEL Kodları: G17, G21, M42 


\section{GiRiş}

Bankalar finansal kaynakların toplanması ve dağıtılmasında etkin faaliyet yürütmeleri dolayısıyla ülke ekonomisinin işleyişinde çok önemli bir işleve sahiptirler. Bankacılık sistemi hem yerel hem de küresel olarak finansal piyasalara yön vermek suretiyle üretim, istihdam ve ekonomik kalkınma yönünde dolaylı veya dolaysız olarak etkilerde bulunmaktadır. Bankalar ulusal ve uluslararası boyutta her türlü değişimden kısa süre içinde ve büyük oranda etkilenebilmektedir. Bankaların finansal durumlarının sürekli olarak takip edilmesi ve muhtemel riskler öngörülerek kısa süre içinde çözülmesi gerekli görülmektedir. Bu durum; toplum, hükümetler ve finansal kuruluşlar açısından sistemin sürdürülebilirliği için önemlidir (Uslu ve diğerleri, 2019).

Bankalar, tasarruf sahiplerinin fonlarını toplamakta ve biriken bu fonları fon ihtiyacı olan kişi ya da kurumlara transfer etmektedir. Bankalar hem kurumsal ve hem de bireysel müşterilerinin taleplerini değerlendirerek onlar için uygun finansman çözümleri sunmaktadır. Bankaların sorunlarla karşılaşması halinde fon transferi doğru bir şekilde işlemeyeceği için tüm ülke ekonomisi etkilenebilmektedir. Finansal sistemin çok önemli bir aktörü olan bankalar finansal serbestleşme uygulamaları sonrasında bazı bankacılık krizlerine maruz kalmışlardır. Finansal serbestleşme aynı zamanda bankacılık sektörünün daha karmaşık bir yapıya bürünmesine sebep olmuştur. Finansal krizler finans kesimi gibi reel kesimi de ciddi oranda etkilemektedir. Bu durumda finansal krizleri ve banka iflaslarını engellemek maksadıyla gözetim ve denetim hususunda belirli kurumlar kurulmuştur. Bu kurumlar, muhtemel riskleri tespit etmek ve önlemek üzere uzaktan gözetim ve yerinde denetim sistemleri geliştirmişlerdir (Şen ve Solak, 2011).

Türkiye'de bankacılık sektörüne yabancı bankaların girişi özellikle 1990'lı yıllardan sonra önemli ölçüde artmıştır. Bunun temel nedenleri olarak, 1980'li yıllarda finansal serbestleşme adımları sonucu ithalat ve ihracattaki artışlar ve Avrupa Birliği ile Gümrük Birliği anlaşmasının devreye girmesi sayılabilir. Bankacılık sektörünün yurtdışına açılması ile yabancı bankaların Türkiye'ye girişleri arasında eşzamanlılık bulunmaktadır. Bu dönemde ayrıca yabancı sermayenin ülkeye girişini kolaylaştırıcı uygulamalar ve kararlar alınmıştır. 1990’lı yıllarda Türk bankacılık sektörüne yabancı bankaların ilgisinin artmasında etkili olan faktörler ise makro ekonomik dengelerde gerçekleşen istikrar ve Avrupa Birliği ile ilişkilerin gelişmesi yönünde mevzuatta bazı düzenlemelerin yapılması neticesinde güven ortamının oluşturulması sayılabilir (Uslu, 2019).

Bankacılık işlemleri genel olarak üretim faktörü olan sermaye, emek ve girişimci gücün birbiriyle uyumlu hareket etmesi yönünde fon transferleri ile aracılık fonksiyonu üstlenmektedir. İstikrarlı bir ekonomik yapı ancak güçlü bir bankacılık sektörü ile mümkün olabilir. Güçlü bir bankacılık için ise bankaların finansal performanslarının doğru ve güvenilir bir biçimde ölçülmesini ve değerlendirilmesini gerektirmektedir (Kaygusuz ve diğerleri, 2020).

Denetim otoriterlerince finansal yenilik ve globalleşmenin sebep olabileceği olumsuz etkileri ortadan kaldırmak üzere alınan önlemler, bankaların denetimleri için yeni bazı düzenlemelerin yapılmasını beraberinde getirmiştir. Yapılan yeni düzenlemelere bağlı olarak yeni sistemler ortaya çıkmaya başlamıştır. Yeni sistemler genel olarak bankaların finansal durumları ile risk faktörünü gözlemlemek, değerlendirmek ve erken uyarı sistemi oluşturmak için kullanılmaktadır. Bankalardaki risk yönetimi uygulamaları ve buna bağlı olarak yapılan gözetim ve denetim işlemleri ülkeden ülkeye farklılık gösterebilmektedir. Her ülkenin uygulaması farklılık taşımakla birlikte genel olarak ortak noktalar üzerinde durulmaktadır. Gözetim ve denetim işlemi "yerinde denetim" (on-site examinations) ve "uzaktan gözetim" (off-site monitoring) olarak iki temel sistem şeklinde belirlenebilir (Emir ve Çizgici Akyüz, 2018).

CAMELS, ABD'de gözetim ve denetim otoritelerince oluşturulmuş olup, ticari bankaların risk unsuru yönünden genel durumlarının belirlenmesinde ve uzaktan gözetim faaliyetinde kullanılmakta olan bir derecelendirme uygulamasıdır. Bu sistem bankaların finansal pozisyonunun; ilgili yasa ve düzenlemelere uyumunu, yönetim kalitesini ve iç kontrol sistemini belirleyen bir uygulamadır. Bu sistem özellikle ABD'de uzaktan gözetim sisteminin önemli bir aracıdır. CAMELS skorları, uygulama neticesinde denetçiler tarafından elde edilen, bir bankanın finansal durumu ile kalitesinin, risk profilinin ve genel performansının göstergesi olarak değerlendirilebilir (Çağıl ve Mukhtarov, 2014).

Bankaların performansını analiz edebilmek için geliştirilen yöntemlerden birisi olan CAMELS değerlendirme sistemi ilk olarak 5 bileşenden oluşmakta iken; 1997 yılından sonra piyasa risklerine karşı duyarlılığın da sisteme dâhil olması ile birlikte sistem, ilk harflerini aldığı 6 bileşenden oluşmaktadır. CAMELS kavramını oluşturan bileşenler; "C" sermaye yeterliğini, " $A$ " aktif (varlık) kalitesini, " $M$ " yönetim yeterliliğini, " $E$ " kazanç durumunu, "L" likidite durumunu, "S" piyasa risklerine karşı duyarlılığı ifade etmektedir (Öztürk Karaçor ve diğerleri, 2017).

Bu çalışmada, ilk olarak bankacılık sektöründe yapılmış CAMELS analizi konusu ile ilgili literatür taraması bilgisine yer verilecek, ardında araştırmanın amacı ve kapsamına değinilecek, daha sonra araştırmanın yöntemi olan CAMELS analizi ile uygulamanın modeline ilişkin bilgiler verilecek olup, son olarak araştırmanın uygulaması gerçekleştirilerek elde edilen bulgular değerlendirilecektir.

\section{LITERATÜR}

Literatürde, bankacılık sektörü için yapılmış CAMELS analizi ile ilgili çalışmalardan bazıları aşağıda özetlenmiştir.

Çinko ve Avcı, Türk Ticari Bankacılık sistemi için CAMELS dereceleme sisteminin uygulanabilirliğini değerlendirdikleri çalışmalarında toplamda 44 banka için 1996-2000 yıllarını kapsayan verileri kullanarak analiz gerçekleştirmişlerdir. Analize dahil bankalardan 19 banka 1997 - 2001 yılları arasında TMSF'ye devredilmiştir. Elde edilen bulgulara göre bir bankanın TMSF'ye devrinin temsili CAMELS oranları kullanılarak tahmin edilebilmesinin mümkün olmadığı şeklindedir. Faaliyetine devam eden bazı bankaların TMSF'ye devredilen bazı bankalara göre daha düşük CAMELS skoru aldığı yönündedir (Çinko ve Avcı, 2008).

Arıçelik, çalışmasında 2002-2009 yılları arasında faaliyette bulunan ticari bankaların performansını CAMELS analizi yöntemiyle değerlendirmiş olup, CAMELS bileşenleri yönünden yapılan değerlendirmede 2002-2009 döneminde en fazla performans artışı gösteren bileşenlerin; aktif 
kalitesi, yönetim kalitesi ve likidite bileşenleri olduğu, belirgin bir değişme görülmeyen bileşenin ise piyasa riskine duyarlılık bileşeni olduğu, toplam CAMELS puanı yönünden 7 bankanın CAMELS puanlarında iyileşme söz konusu iken 6 bankanın puanında gerileme görüldüğü tespit edilmiştir (Arıçelik, 2010).

Şen ve Solak, çalışmalarında 1995-2008 yıllarını kapsayan dönemde mevduat bankalarının kııılganlığında meydana gelen değişimi CAMELS yöntemi kullanarak analiz etmişlerdir. Altı ana bileşen ile ilgili 24 finansal oran kullanılarak gerçekleştirilen çalışmada sonuç olarak; kamu, özel ve yabancı sermayeli bankalar sınıflandırması açısından kamu bankalarının 2001 krizi öncesinde başka bankalara göre çok kötü bir performansa sahip oldukları kriz sonrasında ise performanslarında önemli derecede iyileşme yaşandığı, yabancı sermayeli bankalar sermaye yeterliliği, kârlılık ve likidite kalitesi yönünden küresel krizde başka banka gruplarına göre daha kötü bir performans sergilediği, özel sermayeli bankaların tüm dönemlerde sektör ortalamasının üzerinde bir performansa sahip olduğu tespit edilmiştir (Şen ve Solak, 2011).

Çağıl ve Mukhtarov, 2007-2010 yılları arasında Azerbaycan'da faaliyette bulunan yerli ve yabancı sermayeli bankalar kapsamında CAMELS analizi yapmışlardır. CAMELS ana bileşenleri için toplam 18 finansal oran belirlenmiştir. Çalışmanın neticesine göre yerli sermayeli bankaların yabancı sermayeli bankalara göre daha düşük performansa sahip olduğu, bileşenler itibariyle yerli sermayeli bankaların aktif kalitesi ve piyasa riskine duyarlılık bileşenleri sonuçları yabancı sermayeli bankalara göre daha yüksek skorda olduğu belirlenmiştir (Çağıl ve Mukhtarov, 2014).

Ege ve diğerleri, çalışmalarında, kamu, özel ve yabancı sermayeli mevduat bankalarının finansal durumlarını belirlemek üzere 2002-2010 dönemine ilişkin verileri kullanarak performans ölçümünde CAMELS analizinde kullanılan 25 referans gösterge belirlemek suretiyle gruplara göre karşılaştırmalı analizini yapmışlardır. Elde edilen sonuçlara göre; kamu sermayeli mevduat bankalarının sermaye yeterliliği, piyasa risklerine duyarlılık ve yönetim yeterliliği açısından; özel sermayeli mevduat bankalarının kârlılık bileşeni yönünden ve yabancı sermayeli mevduat banklarının aktif kalitesi ve likidite bileşeni yönünden diğer banka gruplarına göre daha iyi performansa sahip olduğu belirlenmiştir (Ege ve diğerleri, 2015)

Gümüş ve Nalbantoğlu, çalışmalarında Türk Bankacılık Sektörünün 2002-2013 dönemine ilişkin performansını kamu, özel, yabancı ve katılım bankaları olmak üzere CAMELS analiz kullanarak karşılaştırmışlardır. Bulgulara göre özel sermayeli bankalar performans olarak yönetim kalitesi ve kârlılıkta ilk sırada, kamu bankaları ise ikinci sırada yer almıştır. Yabancı bankalarının karlılık ve yönetim kalitesi yönünden zayıf bir görünüme sahip olduğu, katılım bankalarının sermayesinin ise diğer banka gruplarına göre çeşitli nedenlerle güçsüz olduğu değerlendirilmiştir (Gümüş ve Nalbantoğlu, 2015).

Öztürk Karaçor ve diğerleri çalışmalarında Türkiye'de faaliyette bulunan kamusal ve özel sermayeli 12 bankanın grup bazında $2003-2015$ yılları arasındaki performanslarını CAMELS modeli ile analiz etmişlerdir. Genel olarak kamusal sermayeli banka grubunun aktif kalitesi bileşeni dışında daha iyi performans gösterdiği tespit edilmiştir (Öztürk Karaçor ve diğerleri, 2017).

Bayramoğlu ve Gürsoy, çalışmalarında 2005-2015 yıllarını kapsayan süreçte faaliyette olan 25 mevduat bankasının risk-performans analizini CAMELS yöntemi ile yapmışlardır. Elde edilen bulgulara göre; özel bankaların sermaye yeterliliği ve likidite durumu bileşenlerine göre güçlü olduğu, yönetim kalitesi bileşenine göre ise zayıf olduğu; yabancı bankaların varlık kalitesi ve piyasa riskine duyarlılık bileşenlerine göre güçlü olduğu, yönetim kalitesi ve likidite durumu bileşenlerine göre zayıf olduğu belirlenmiştir. Tüm bankacılık sektörü yönünden bulgular ise, varlık kalitesi, sermaye yeterliliği ve likidite durumu bileşenleri yönünden güçlü, yönetim kalitesi ve piyasa riskine duyarlılık yönünden zayıf olduğu tespit edilmiştir (Bayramoğlu ve Gürsoy, 2017).

Emir ve Akyüz, CAMELS analizi uyguladıkları çalışmalarında Türkiye'de faaliyette bulunan mevduat bankalarının performans endekslerini oluşturmak üzere 22 mevduat bankasına ait 2003:Q3-2016:Q2 dönemi verilerini kullanmışlardır. Bankalara hem genel olarak hem de gruplar itibariyle CAMELS analizi gerçekleştirmişlerdir. Elde edilen bulgulara göre; yabancı sermayeli mevduat bankalarının sermaye yeterliliği, aktif kalitesi ve likidite bileşenlerinde, kamu sermayeli mevduat bankalarının yönetim kabiliyeti ile karlılık bileşeninde, özel sermayeli mevduat bankalarının ise piyasa riskine duyarlılık bileşeninde en yüksek performansa sahip olduğu belirlenmiştir (Emir ve Çizgici Akyüz, 2018).

Şendurur ve Temelli yapmış oldukları çalışmada, CAMEL analizi ile 2010-2016 yılları arasında Türkiye'de faaliyet gösteren 7 geleneksel banka ile 5 katılım bankasını karşılaştırmışlardır. Analizde 10 finansal oran kullanılmıştır. Elde edilen verilere t-testi uygulanarak geleneksel ve katılım bankalarının birbirinden farklılaşma durumu araştırılmıştır. Analiz sonucunda geleneksel bankaların kârlılık, likidite, sermaye yeterliliği ve yönetimin etkinliği yönünden katılım bankalarına göre daha iyi performansa sahip olduğu görülmüş olmakla birlikte varlık kalitesi bileşeni yönünden katılım bankalarının daha iyi performansa sahip olduğu tespit edilmiştir (Şendurur ve Temelli, 2018).

Uslu yapmış olduğu çalışmada Türkiye'de kurulmuş bulunan 12 yabancı sermayeli bankanın 2010-2016 yıllarını kapsayan performanslarını uzaktan denetim ve izleme amacıyla geliştirilen CAMELS analizi ile ölçmüştür. Elde edilen sonuçlara göre CAMELS analizi ile yabancı bankaların performansları değerlendirilmiş ve \% 50'sinde 2010 yılına göre 2016 yılında performans düşüşü olduğu, performansı en çok artan ilk üç bankanın Deutsche Bank, Citibank ve Turkland Bank olduğu, öte yandan Deutsche Bank'ın puanlarının diğer bankalara göre daha büyük kırılganlıklar gösterdiği tespit edilmiştir (Uslu, 2019).

Akyüz ve diğerleri çalışmalarında katılım bankalarının 2013-2017 yılları arasında CAMELS Analizi ile performanslarını ölçmüşlerdir. Analiz sonucunda, her banka için ayrı ayrı değerlendirme yapıldıktan sonra genel olarak analiz edilen katılım bankalarının CAMELS puanlarının 2015 yılından itibaren düştüğü tespit edilmiştir (Akyüz ve diğerleri, 2020).

\section{VERI VE YÖNTEM}

Bu çalışmanın amacı fon arz edenler ile fon talep edenler arasında fon transferinin gerçekleştirilmesi için çalışan, ülke ekonomisinin gelişmesine kaynak temin eden ve finansal piyasada önemli bir yeri olan yabancı sermayeli mevduat bankalarının finansal performanslarını analiz ederek, bileşenlerin etki durumunu belirlemektir. Bu araştırma çalışmasında Türkiye'de faaliyette bulunan yabancı sermayeli mevduat 
bankalarının 2009-2019 yılları arasında 11 yıllık süreyi içeren dönemde bileşen odaklı olarak CAMELS analizi ile finansal performanslarının ölçülmesi amaçlanmıştır. Araştırmaya dâhil örneklemi oluşturan yabancı sermayeli mevduat bankalarının listesi; Alternatifbank A.Ş., Arap Türk Bankası A.Ş., Burgan Bank A.Ş., Citibank A.Ş., Denizbank A.Ş., Deutsche Bank A.Ş., HSBC Bank A.Ş., ICBC Turkey Bank A.Ş., ING Bank A.Ş., QNB Finansbank A.Ş., Turkland Bank A.Ş., Türkiye Garanti Bankası A.Ş. şeklindedir.

Türkiye'de kurulmuş mevduat bankacılığı yapan toplam 21 yabancı sermayeli banka mevcut olup, bunlardan 5 tanesinin şube bankacılığı yapması ve 4 tanesinin ise analize konu yıllar itibariyle verilerinin tam olmaması dolayısıyla uygulama çalışmasında 12 yabancı sermayeli mevduat bankası değerlendirilmiştir. Analize dahil olan tüm bankaların ilgili finansal oranları Türkiye Bankalar Birliği tarafından hazırlanan Türkiye'de bankacılık sistemi "Seçilmiş Rasyolar" 2009-2019 raporundan sağlanmıştır.

Bankaların denetim ve gözetimine ilişkin yöntemler ülkelere göre farklılık göstermekle beraber uygulamada iki temel sistem değerlendirilmektedir. Bunlar; "yerinde denetim (on-site)" ve "uzaktan gözetim (off-site)" sistemleridir. Uzaktan gözetim sistemleri bankaların sürekli ve düzenli olarak kontrol edilmesi, finansal yapılarının sağlam olup olmadığının belirlenmesi ve genel ekonomiyi etkileyebilecek bankacılık sektörü kökenli olumsuzluklar öngörülerek tedbir alınması amacıyla geliştirilmiştir. Bu sistemler bankaların finansal raporlarındaki kalemlerin ve oranların değişik yöntemlerle analiz edilmesi ve yorumlanması şeklinde gerçekleştirilmektedir. Bankaların sağlam oluşu ve güvenilirliği hem finansal sistem için hem de genel ekonomi bakımından önemli görülmektedir. Bankaların incelenmesi ile ilgili olarak yerinde denetim yapılmasının yüksek maliyetler ve yoğun emek gerektirdiği, dolayısıyla bankaların uzaktan denetimlerinin daha uygun olabileceği öngörülmektedir. Buna rağmen, bankalar ihtiyaç duymaları halinde yerinde denetim de yapmaktadırlar (Çinko ve Avcı, 2008, Şen ve Solak, 2011).

CAMELS sistemi ilk olarak ortaya çıktığında 5 bileşenden oluşmakta iken 1997 yılından sonra piyasa risklerine karşı duyarlılığın da sisteme eklenmesiyle birlikte sistem 6 bileşeni bünyesinde barındırmaya başlamıştır (Öztürk Karaçor ve diğerleri, 2017). Belirtilen bileşenler; C (Capital) sermaye yeterliliği, A (Asset) aktif kalitesi, M (Management) yönetim kalitesi, E (Earnings) kazanç, L (Liquidity) likidite durumu ve S (Sensitivity to Market Risk) piyasa riskine duyarlılığı açıklanmaktadır (Şen ve Solak, 2011);

Belirtilen bileşenler için çeşitli finansal oranlar kullanılmaktadır. Değerlendirme 1 ila 5 arası bir ölçek üzerinden yapılmaktadır. İlgili bileşende en iyi not "1" ile ifade edilmektedir. Notun artması riskin de arttığı anlamına gelmektedir. Bu bileşenlerin ağırlıklı ortalaması ise bankanın genel skorunu vermektedir. Buna göre; "1" Her yönden güçlü bankaları (Her bir bileşen notu 1 veya 2 olmalı), "2" Genel olarak güçlü bankaları (Her bir bileşen notu 3'ten kötü olmamalı), "3" performansı ile ilgili problemlerin yaşandığı bankaları, "4" Genel olarak ciddi problemleri olan ve finansal/yönetimsel bozulmaların yaşandığı bankaları, " 5 " Çok ciddi finansal ve yönetimsel problemlerin yaşandığı bankaları ifade etmektedir. CAMELS bileşenlerinin değerlendirilmesi sürecinde bankanın büyüklüğü, kurumsal yapısı, risk profili de analize dâhil edilmekte olup, bununla bankaların gerçek durumlarının azami ölçüde yansıtılması amaçlanmaktadır (Arıçelik, 2010).

CAMELS uygulama çalışmasında Türkiye bankacılık sisteminde faaliyet gösteren yabancı sermayeli mevduat bankalarının $2009-2019$ dönemine ait finansal verileri kullanılmıştır. Uygulama dönemi olan 2009-2019 yılları arasında aktif olmadıkları veya veri yönünden aşırı bir miktar gösterdiği tespit edilen bankalar, veri setleri tam olmadığı veya analize doğru neticenin alınmasında katkı sağlamayacağı düşünüldüğü için değerlendirmeye alınmamıştır. Dolayısıyla çalışma, toplamda Türkiye'de kurulmuş 12 adet yabancı sermayeli mevduat bankası ile yapılmıştır. İlgili bankaların 2009-2019 dönemine ait bilanço ve gelir tabloları kullanılarak elde edilen 22 mali oranla CAMELS analizi çalışması gerçekleştirilmiştir. Uygulama çalışmasında her bir bileşen için ayrı olmak üzere bileşen odaklı bir yaklaşım benimsenmiştir. Bu doğrultuda odak alınan bileşen \%50 ağırlıklı olarak belirlenmiş, diğer bileşenler ise \%10 olarak eşit ağırlıklı değerlendirilerek analiz gerçekleştirilmiştir.

Araştırma çalışmasının modeli ile ilgili olarak yabancı sermayeli mevduat bankalarının bileşen faktörleri; Sermaye Yeterliliği (C), Aktif Kalitesi (A), Yönetim Kalitesi (M), Karlılık (E), Likidite (L), Piyasa Risklerine Duyarlılık (S) harfleri ile ifade edilmektedir. Literatürde başka araştırmalarda da kullanımış finansal oranlar dikkate alınarak belirtilen bileşen faktör konuları ile veri setleri oluşturulmuştur. Çalışmanın analiz uygulamasında kullanılan bileşenler, bileşenleri oluşturan değişkenler ve etki oranları Tablo 4.'te gösterilmektedir.

Tablo 4: Analizde Kullanılan Finansal Oranlar ve Ağırlıkları

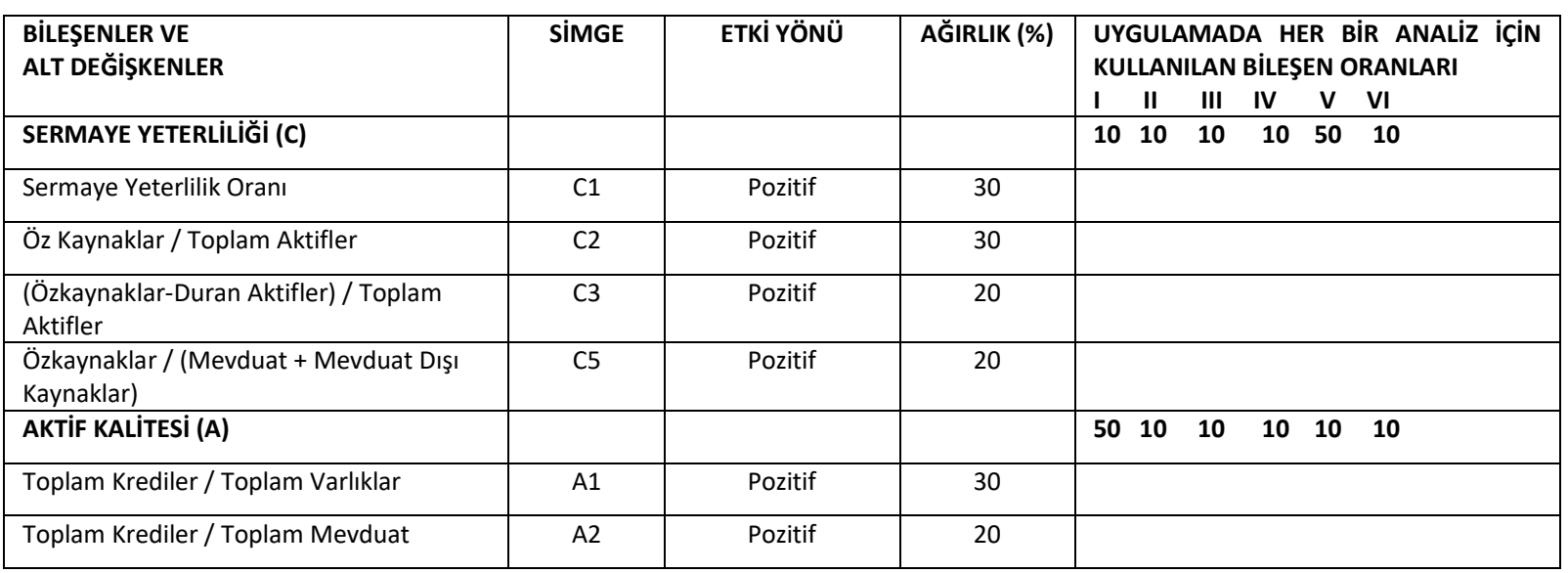




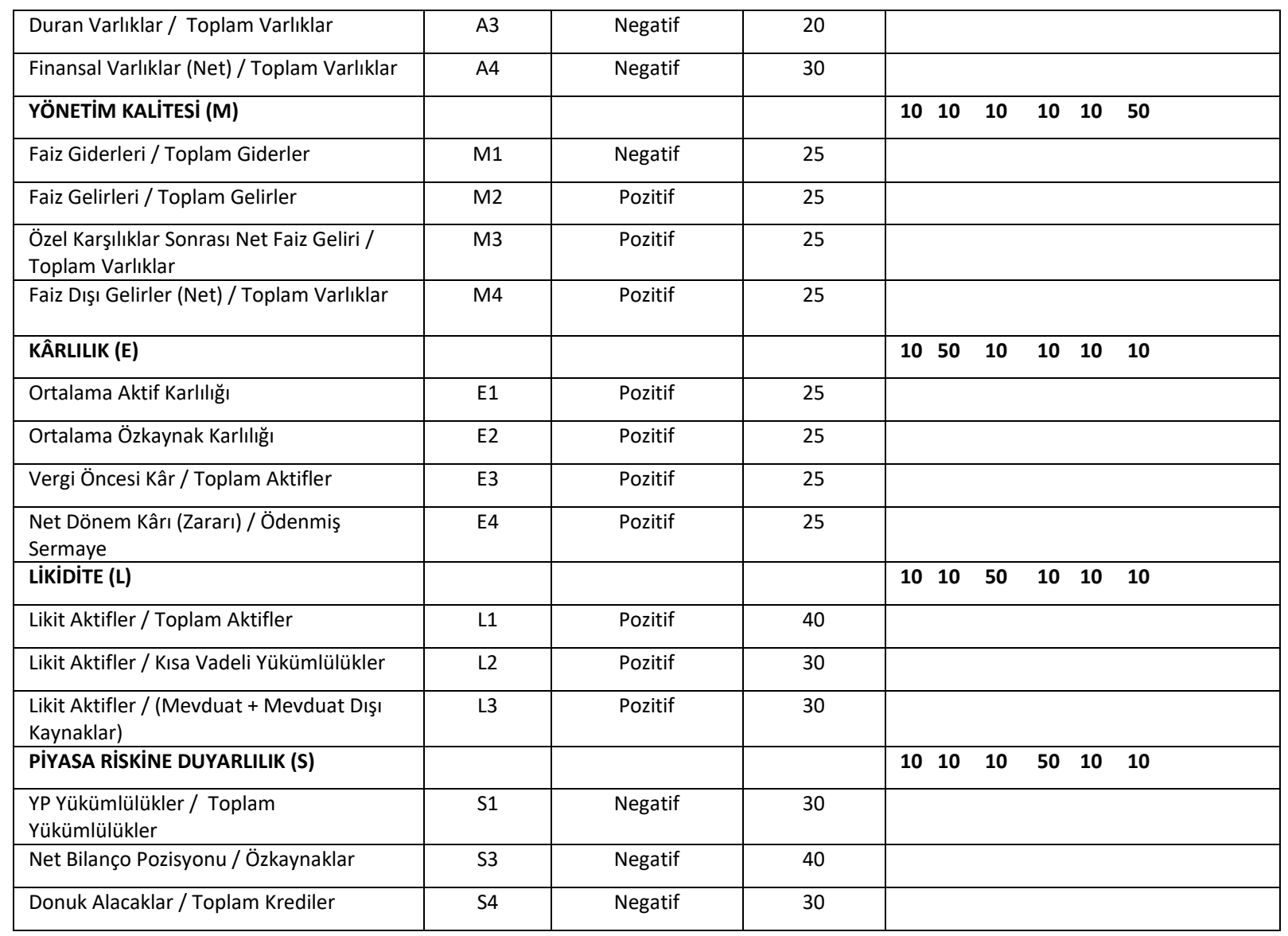

Uygulama ile bankaların performanslarının belirlenmesi ve CAMELS puanının bulunması belirli hesaplama aşamaları neticesinde sağlanmaktadır. Bu konuda referans değeri, endeks değeri, sapma değeri, genel faktör ağılıklı değeri, CAMELS gösterge değeri hesaplanarak, sonuçta CAMELS puanı bulunmaktadır. CAMELS puanının hesaplanma ayrıntıları ve aşamaları Tablo 5'te gösterilmektedir.

Tablo 5: CAMELS Analizi Uygulama Aşamaları

\begin{tabular}{|l|c|l|}
\hline Açıklama & Aşaması & Uygulama yönergesi \\
\hline $\begin{array}{l}\text { Genel faktörün bileşenleri finansal } \\
\text { oranların saptanması }\end{array}$ & A & $\begin{array}{l}\text { Literatürde uygulama durumu da değerlendirilerek genel faktör ile ilgili finansal } \\
\text { oranlar belirlenir }\end{array}$ \\
\hline Etki yönünün belirlenmesi & B & $\begin{array}{l}\text { Finansal oranda meydana gelen değişimin genel faktör üzerinde pozitif veya negatif } \\
\text { etkisinin saptanması }\end{array}$ \\
\hline Genel faktörün ağırlı̆̆ının belirlenmesi & C & Toplam analiz çerçevesinde genel faktörün ağılı̆̆ının belirlenmesi \\
\hline Finansal Orana Verilen Ağılık (\%) & D & Finansal oranın ilgili faktör içindeki eti oranının belirlenmesi \\
\hline Referans Değeri & E & $\begin{array}{l}\text { Hesaplanan döneme ilişkin uygulama örneklemi bankaların ilgili finansal oranlarının } \\
\text { aritmetik ortalaması }\end{array}$ \\
\hline Endeks Değeri & G & $\begin{array}{l}\text { Finansal oranın referans değere bölünmesi ve 100 ile çarpılması sonucu elde edilen } \\
\text { değer }\end{array}$ \\
\hline Sapma Değeri & H & $\begin{array}{l}\text { Ilişki yönü pozitif ise endeks değer-100 } \\
\text { ilişki yönü negatif ise; 100- endeks değer şeklinde bulunan değer }\end{array}$ \\
\hline Ağırıklı Değerler & I & Finansal oranın etki oranı ile sapma değerin çarpılması sonucu bulunan değer \\
\hline Genel Faktör Ağırlık Değeri & J & $\begin{array}{l}\text { Her bir finansal oran için elde edilen ağırlıkı̆ değerin toplanarak genel faktör etki } \\
\text { oranı ile çarpılması sonucu ortaya çıkan değer }\end{array}$ \\
\hline CAMEL Gösterge Değeri & K & $\begin{array}{l}\text { Her bir genel faktör ağırlıklı değerinin toplamının alınması sonucu ortaya çıkan } \\
\text { değer }\end{array}$ \\
\hline CAMELS Puanı & L & $\begin{array}{l}\text { Her bir banka için bulunan CAMELS gösterge değerinin 1-5 arasında puanlanarak } \\
\text { ilgili bankanın kapsamdaki diğer bankalara göre performans puanının belirlenmesi }\end{array}$ \\
\hline
\end{tabular}

Kaynak: Arıçelik, 2010; Kandemir ve Demirel Arııı, 2013; Akyüz ve diğerleri, 2020 


\section{BULGULAR}

Araştırma çalışmasında yabancı sermayeli mevduat bankalarının performanslarının ölçümü için CAMELS analizi uygulanmıştır. Yapılan analizde Tablo 3.'te belirtilen bankalarla ilgili olarak Tablo 4'te belirtilen finansal oranlar ve ağırıkları kullanılarak Tablo 5'teki uygulama aşamaları ile modelin hesaplaması yapılmaktadır.

2009-2019 yılları arasında faaliyette bulunan Türkiye'de kurulmuş 12 yabancı sermayeli mevduat bankası ile analiz gerçekleştirilmiştir. i̇lgili bankaların 2009-2019 dönemine ait bilanço ve gelir tabloları kullanılarak elde edilen 22 mali oranla CAMELS analizi çalışması yapılmıştır. Uygulama çalışmasında her bir bileşen için ayrı odaklı olmak üzere 6 ayrı analiz gerçekleştirilmiştir. 1. Analizde "Aktif Kalitesi” odaklı yaklaşım, 2. Analizde "Kârlılık" odaklı yaklaşım, 3. Analizde "Likidite" odaklı yaklaşım, 4. Analizde "Piyasa Risklerine Duyarlılık" odaklı yaklaşım, 5. Analizde "Sermaye Yeterliliği" odaklı yaklaşım ve 6. Analizde ise "Yönetim Kalitesi" odaklı yaklaşım benimsenmiştir. Bu doğrultuda odak oluşturulan bileşen \%50 ağırlıklı olup, diğer bileşenlerin her birine eşit ağırlıklı olarak \%10 ağırlık uygulanarak hesaplama yapılmak suretiyle CAMELS analizi gerçekleştirilmiştir. Bankaların 2009-2019 yılları itibariyle 11 yıllık süreci kapsayan analize dahil tüm yabancı sermayeli bankaların CAMELS Göster Değeri 6 farklı analizde hesaplanmıştır. Uygulama çalışmasındaki bankalar için ayrı ayrı 6 farklı odaklı yaklaşım ile elde edilen analiz sonucuna göre CAMELS Göster Değeri gelişim eğilimi belirlenmiştir.

Uygulama çalışmasında her bir bileşen için ayrı olmak üzere bileşen odaklı bir yaklaşım benimsenerek odak alınan bileşen \%50 ağırlıklı olarak belirlenmiş, diğer bileşenler ise \%10 olmak üzere eşit ağırıklı değerlendirilmiştir. Uygulama çalışmasındaki bankalar için ayrı ayrı 6 farklı analiz sonucuna göre CAMELS Göster Değeri gelişim eğilimi yönünden elde edilen veriler ışığında yapılan değerlendirmede bankalar itibariyle aşağıdaki sonuçlar elde edilmiştir:

- $\quad$ Alternatifbank A.Ş., ortalama aktif kârlılık oranı gelişim eğilimine göre CAMELS değeri ile tam olarak örtüşmediği, dolayısıyla bu bileşenlerin baskın bir özellikte olmadığı,

- $\quad$ Arap Türk Bankası A.Ş., ortalama aktif kârlılık oranı gelişim eğilimi ile CAMELS değeri tam olarak örtüşmediği ve karmaşık bir özellikte olduğu izlenimi verdiği,

- Burgan Bank A.Ş., ortalama aktif kârlılık oranı gelişim eğilimi ile CAMELS değeri ile örtüştüğü, dolayısıyla kârlılık bileşeninin oldukça baskın olduğu,

- C Citibank A.Ş., ortalama aktif kârlılık oranı gelişim eğilimi ile CAMELS değeri tam olarak örtüşmediği, baskın olmadığı karmaşık etkili bir özellikte olduğu,

- Denizbank A.Ş., ortalama aktif kârlılık oranı gelişim eğilimi ile CAMELS değerinin örtüştüğü, dolayısıyla bu bileşenin baskın bir özellikte olduğu,

- Deutsche Bank A.Ş., ortalama aktif kârlılık oranı gelişim eğilimi ile CAMELS değeri genellikle örtüşmekle birlikte karmaşık etkiye sahip olduğu,

- $\quad$ HSBC Bank A.Ş., ortalama aktif kârlılık oranı gelişim eğilimi ile CAMELS değeri genellikle örtüştüğü, ancak bazen karmaşık etkiye sahip bir özellikte olduğu,

- $\quad$ ICBC Turkey Bank A.Ş., ortalama aktif kârlılık oranı gelişim eğilimi ile CAMELS değeri büyük ölçüde örtüştüğü, dolayısıyla kârlılık bileşeninin baskın bir özellikte olduğu,

- ING Bank A.Ş., ortalama aktif kârlılık oranı gelişim eğilimi ile CAMELS değeri tam olarak örtüşmediği, dolayısıyla baskın özellikte olmadığı ve karmaşık bir özellikte olduğu,

- QNB Finansbank A.Ş., ortalama aktif kârlılık oranı gelişim eğilimi ile CAMELS değeri tam olarak örtüşmediği, dolayısıyla belli ölçüde baskın bir özellikte olduğu,

- Turkland Bank A.Ş., ortalama aktif kârlılık oranı gelişim eğilimi ile CAMELS değeri 2009-2017 döneminde karmaşık bir özellikte olduğu,

- Türkiye Garanti Bankası A.Ş., ortalama aktif kârlılık oranı gelişim eğilimi ile CAMELS değeri tam olarak örtüşmediği, dolayısıyla bu bileşenlerin baskın bir özellikte olmadığı,

şeklinde yorum yapılabilir.

\section{SONUÇ}

Türkiye'de 1980'lerden günümüze değin geçen sürede bankacılık sektörü içerisinde yabancı sermayeli bankaların sayısı yıllar itibariyle gelişme göstermiştir. 1980 yılında 4 olan yabancı sermayeli mevduat banka sayısı 2000 yılı sonu itibariyle 18 ve 2020 yılı itibariyle 21'e yükselmiş olup yaklaşık 52.000 kişi istihdam ile bankacııık sektöründe çalışanların yüzde $26^{\prime}$ sını oluşturmaktadır. Yabancı sermayeli mevduat bankalarının yanı sıra 4 adet yabancı kalkınma ve yatııım bankası da bulunmaktadır. Mevduat bankalarının aktiflerinin sektör içindeki payı yüzde 87, kalkınma ve yatırım bankalarının payı yüzde 6 , katılım bankalarının payı ise yüzde 7 şeklindedir. Kamu sermayeli mevduat bankalarının aktifler içindeki payı yüzde 38, özel sermayeli mevduat bankalarının payı yüzde 28, yabancı sermayeli mevduat bankalarının payı ise yüzde 20 şeklindedir. Yabancı sermayeli bankalar sektör içindeki payı itibariyle hem aktiflerde, hem kredilerde hem de mevduatta sektör payı yüzde 20 civarındadır. Bu durumda Türk bankacılık sektöründe önemli bir orana sahip yabancı sermayeli bankaların mevcut durumunun değerlendirilmesi ve analize konu edilmesi Türkiye ekonomisinde kapsadığı alan itibariyle önemli görülmektedir. Belirtilen gerekçelerle bu çalışmada yabancı sermayeli bankalar ile ilgili analiz gerçekleştirilmiştir.

Sonuç olarak elde edilen veriler ışığında, bankaların odak olarak belirlenen bileşeninin diğer bileşenler üzerinde nasıl bir etkiye sahip olduğu değerlendirilmiştir. Bu bilgilerle, analiz kapsamındaki bankalarda yıllar itibariyle büyük ölçüde kârlıık bileşeninin baskın bir yapıda olduğu, dolayısıyla aktif kârılıı oranında değişimin diğer bileşenlerde büyük ölçüde etkili olduğu belirlenmiştir. Elde edilen sonuçlar bir tarafta banka yetkililerine yol gösterirken, öte yandan banka yöneticilerine finansal durumu yorumlayarak gerekli tedbirlerin alınması ile ilgili ipuçları da 
verebilir. Yapılan bu çalışma, bankalarla ilgili CAMELS analizinin bileşen odakıı uygulama olması yönüyle özgün bir yapıya sahiptir. CAMELS derecelendirme yönteminin farklı ağırlık katsayıları ve bileşenler itibariyle hesaplanarak değerlendirilmek suretiyle daha hassas bilgi ve ipuçları da verebilir. Yapılan bu çalışma, bankalarla ilgili CAMELS analizinin bileşen odaklı uygulama olması yönüyle özgün bir yapıya sahiptir. CAMELS derecelendirme yönteminin farklı ağılık katsayıları ve bileşenler itibariyle hesaplanarak değerlendirilmek suretiyle daha hassas bilgi ve ipuçlarına ulaşma imkânı verebileceği, dolayısıyla araştırmacılar açısından ilerleyen süreçte farklı araştırmalar yapılması imkânı sağlayacağı öngörülmektedir.

\section{KAYNAKÇA}

Akyüz, F., Soba, A., Yeşil, T. (2020). Katılım Bankalarının CAMELS Analizi Yöntemiyle Finansal Performanslarının Değerlendirilmesi. Muhasebe ve Finansman Dergisi. (87), 145 - 166

Arıçelik, G. (2010). Ticari Bankalarda Performans Ölçümü: CAMELS Analizine Dayalı Bir İnceleme. Dokuz Eylül Üniversitesi Sosyal Bilimler Enstitüsü. (yayınlanmamış yüksek lisans tezi). İzmir.

Bayramoğlu, M. F. \& Gürsoy, İ, (2017). Türkiye'de Faaliyet Gösteren Mevduat Bankalarının Bireysel ve Sektörel Risk Derecelendirmesi: Bir CAMELS Analizi Uygulaması. Yönetim ve Ekonomi Araştırmaları Dergisi. 15(1). 15(1), 1-19.

Çağıl, G. \& Mukhtarov, S. (2014). Azerbaycan Ticari Bankacılık Sektörünün CAMELS Yöntemi ile Performans Analizi. Marmara Üniversitesi Öneri Dergisi. 11(41), $77-94$.

Çinko M. \& E. Avcı (2008). CAMELS Dereceleme Sistemi ve Türk Ticari Bankacılık Sektöründe Başarısızlık Tahmini. BDDK Bankacılık ve Finansal Piyasalar. 2(2), $25-48$

Çizgici Akyüz, G. \& Emir, M. (2018). Türkiye'deki Mevduat Bankalarının Finansal Performans Değerlendirmesi: Camels Yaklaşımı. Karadeniz Teknik Üniversitesi Sosyal Bilimler Enstitüsü Sosyal Bilimler Dergisi. 8 (15), 7 - 26.

Ege, I., Topaloğlu, E.E. \& Karakozak, Ö. (2015). CAMELS Performans Değerleme Modeli: Türkiye'deki Mevduat Bankaları Üzerine Ampirik Bir Uygulama. Niğde Üniversitesi iktisadi ve Idari Bilimler Fakültesi Dergisi. 8(4), 109 - 126.

Gümüş, F. B. \& Nalbantoğlu, Ö. (2015). Türk Bankacılık Sektörünün CAMELS Analizi Yöntemiyle 2002-2013 Yılları Arasında Performans Analizi. Afyon Kocatepe Üniversitesi iiBF Dergisi. 17(2), 83-106.

Kandemir, T. \& Arıcı, A. (2013). Mevduat Bankalarında CAMELS Performans Değerleme Modeli Üzerine Karşılaştırmalı Bir Çalışma (20012010). Süleyman Demirel Üniversitesi Iktisadi ve Idari Bilimler Fakültesi Dergisi. 18 (1), 61 - 87.

Karahanoğlu, İ. (2017). Türk Kalkınma ve Yatırım Bankalarının Aktif Karlılığını Etkileyen Faktörlerin Belirlenmesi. Erciyes Üniversitesi iktisadi ve Idari Bilimler Fakültesi Dergisi. (50), 167 - 186.

Kaygusuz, M., Ersoy, B. \& Bozdoğan, T. (2020). CAMELS Değerlendirme Sistemiyle Bankaların Finansal Performanslarının TOPSis Yöntemiyle Analizi. Insan ve Toplum Bilimleri Araştırmaları Dergisi. 9 (1), 67-95.

Öztürk Karaçor, Z., Mangır, F., Kodaz, Ş. \& Kartal, M. (2018). Kamusal ve Özel Sermayeli Bankaların CAMELS Performans Analizi: Türkiye Örneği. İstanbul Gelişim Üniversitesi Sosyal Bilimler Dergisi. ICEFM 2017 Özel Sayısı, 4(2), 47 - 65

Şen, A. \& Solak, S. (2011). Ticari bankacılık sektörünün CAMELS analizi: Türkiye örneği. Finans Politik ve Ekonomik Yorumlar Dergisi. 48(554), $51-70$.

Şendurur, U. \& Temelli, F. (2018). CAMEL Derecelendirme Modeli Yardımı İle Türkiye'de Faaliyet Gösteren Geleneksel Bankalar ve Katılım Bankalarının Karşılaştırmalı Analizi. Ulakbilge. 6(23), 525-543.

Şenel, C. \& Şekeroğlu, S. (2019). Yatırım ve Kalkınma Bankalarının Etkinliklerinin VZA Yöntemiyle Analizi ve Türk Bankacılık Sektöründe Bir Uygulama. Üçüncü Sektör Sosyal Ekonomi Dergisi. 54(1), 565 - 580.

Uslu, A. (2019). Türkiye'deki Yabancı Sermayeli Bankaların CAMELS Analizi ile Performanslarının Ölçümü. Muhasebe ve Finansman Dergisi, (82), $199-220$.

Uslu A., Türk M. \& Ertaş F. C. (2019). Türkiye'deki Mevduat Bankalarının CAMELS Performans Analizi. BMIJ, (2019), 7 (3), $122-139$.

Türkiye Bankalar Birliği (2020a). Türkiye'de Bankacılık Sistemi Seçilmiş Rasyolar 2009-2019. Rapor Kodu: YT05

Türkiye Bankalar Birliği. Bankalarımız (2020b). (https://www.tbb.org.tr/Content/Upload/Dokuman/7766/Bankalarimiz_2020.pdf) Erişim tarihi:13.0512021. Yayın No:339, Mayıs 2021 İstanbul 